\title{
Soft-Switching Vector Control for Resonant Snubber Based Inverters
}

\author{
C.C. Chan, K.T. Chau and Jianming Yao \\ Department of Electrical and Electronic Engineering \\ The University of Hong Kong \\ Pokfulam, HONG KONG
}

\begin{abstract}
This paper gives a new classification of soft-switching inverters according to the principle of operation. After discussing the soft-switching phenomena in hard-switching inverters, the concept of soft-switching vector (SSV) is introduced. The proposed SSV is not only helpful in analyzing the changes of switching states, but also easily realized in control scheme. Theoretical analyses are conducted step by step for both with and without SSV control applied to resonant snubber based inverters (RSI). The experimental results closely agree with theoretical analyses and show the significant reduction in power loss after using SSV. Moreover, a modified version of SSV is also presented to achieve the better working condition at low load current with current ripple.
\end{abstract}

\section{INTRODUCTION}

A number of soft-switching inverters have been proposed in recent years [1]-[5]. It is noted that most of the research on soft-switching inverters focus on the voltage source inverters (VSI) and with the aim of achieving zero voltage switching (ZVS) when turning on. VSI are commonly used in industrial applications, such as the propulsion system for electric vehicles. Therefore this paper will also pay its attention to ZVS when studying soft-switching. On the other hand, the study of zero current switching (ZCS) turning off is similar to those of ZVS and can be easily derived by using the principle of duality [6]. According to the topologies, soft-switching inverters are normally classified into two families, namely the resonant DC-link inverter family and resonant snubber based inverter family as stated in [4].

The milestone of the development of soft-switching inverters is believed to be the resonant DC-link (RDCL) inverter which has been developed for over a decade [1]. It has been well known that its major drawback has been the high voltage or current stress. Some modified versions also appeared afterwards, but they still limit themselves in producing resonance at DC-link and require the main switches to operate synchronously so that they cannot readily use the well-established pulse width modulation (PWM) techniques.

By using auxiliary switches and inductors along with lossless resonant snubber capacitors to achieve soft-switching at the device side or the load side, various topologies of auxiliary resonant snubber based soft-switching inverters have been proposed in [2]-[5]. In general, the parasitic inductance and stray capacitance of these inverters are utilized as a part of the resonant components, while there are no over-voltage or over-current penalty in the main inverter switches. Thus, these soft-switching inverters potentially achieve high-efficiency power conversions in a cost-effective way of soft-switching. Nevertheless, they still have some problems which should be tackled before widely acceptable for industrial applications. Among them, the delta-configured resonant snubber inverter $(\Delta-\mathrm{RSI})$ is a very attractive one because of the advantages of no floating-voltage/over-voltage penalty on the auxiliary switches, no need of using additional voltage/current sensors, and no need of using anti-paralleled fast reverse recovery diodes across the resonant switches [5]. However, it realizes ZVS in the main circuit while brings additional power loss and EMI in the auxiliary circuit. Also, this inverter may have the over-current problem on the main switches during resonant periods. Therefore, its control scheme should be further improved.

Up to now, there have been a number of viable softswitching inverter topologies. Although research on softswitching inverter topologies is still an interesting topic, another viable topic is how to fully utilize the existing softswitching topologies and switching schemes, and then to find an effective way of control for the inverter itself with the coordination between the operations of main switches and auxiliary switches.

It is the purpose of this paper to propose a new classification of soft-switching inverters according to their operation principles. This can be helpful to discuss in depth how the soft-switching takes place. With the analysis of softswitching phenomena in conventional hard-switching inverters, a new concept of soft-switching vector (SSV) is introduced for analyzing the switching state changes and realizing in the control schemes for the resonant snubber based inverter family. After applying the SSV control, the operation modes can be simplified while maintaining fully ZVS for the main switches. This causes the significant reduction of power loss in both main circuit and auxiliary circuit. Taking $\Delta$-RSI for exemplification, theoretical analysis is conducted step by step to compare the operation modes with and without SSV control. Hardware implementation and experiments are carried out to verify the theoretical analysis. 


\section{SOFT-SWITCHING VECTOR}

\section{A. A New Classification of Soft-Switching Inverters}

Previous classification of soft-switching inverters is based on the topologies and cannot reveal their principles of operation. After studying their principles of operation, a new classification can be derived. To achieve ZVS, the resonant DC-link inverters all operate their main switches when the DC-link voltage becomes zero. In one inverter leg, there should always be a main switch with zero voltage while another with full DC-link voltage before the changing of switching states. If the DC-link voltage becomes zero, then all the voltage across the main devices are zero. Therefore, the operation of switching state changes can be carried out at ZVS. This kind of inverters can be called "link zero" type.

According to the topologies and operating principles, three vital auxiliary resonant snubber based inverters are identified:

- auxiliary resonant commutated pole (ARCP) inverter;

- zero-voltage transition (ZVT) inverter;

- star/delta-configured resonant snubber inverter(Y/A-RSI).

For their common features, auxiliary switches, snubber capacitors and resonant inductors, the resonance is moved to take place at the load side or device side, with the participation of auxiliary inductors and snubber capacitors and control by the switching of auxiliary switches. The auxiliary inductors must be charged with enough energy, then the resonance with the snubber capacitors begins. As a result, the snubber capacitor paralleled with the main switch will be discharged to zero voltage. The anti-paralleled diode will then be turned on and the auxiliary inductors current will be diverted to pass through this diode. With such kind of artificial diode free-wheeling, the desired switch can be readily turned on with ZVS. This type of inverters can generally be called as "device zero" type or, more specifically, "diode free-wheeling ZVS" inverters.

It is noted that "diode free-wheeling" is playing an active role in most of the soft-switching inverters, even in some ZCS inverters.

\section{B. Soft-Switching Phenomena in Hard-Switching Inverters}

For hard-switching PWM, there are four states corresponding to the combination of switching states for the leg of the inverter as shown in Fig 1.

- State $I-\mathrm{S}_{1}$ on and $\mathrm{S}_{3}$ off for $\mathrm{I}_{\text {load }}>0$

- State II $-\mathrm{D}_{1}$ on and $\mathrm{S}_{3}$ off for $\mathrm{I}_{\text {load }}<0$

- State III - $\mathrm{S}_{1}$ off and $\mathrm{D}_{3}$ on for $\mathrm{I}_{\mathrm{load}}>0$

- State $I V-\mathrm{S}_{1}$ off and $\mathrm{S}_{3}$ on for $\mathrm{I}_{\text {load }}<0$

When there are changes from State I to State III (Case 1) and from State IV to State II (Case 4), the main switches $\mathrm{S}_{3}$ and $\mathrm{S}_{1}$ can be readily turned on at ZVS condition because there are natural freewheeling via $D_{3}$ and $D_{1}$ after turning off the switches of $S_{1}$ and $S_{3}$, respectively. On the other hand, when there are changes from State III to State I (Case 2) and from State II to State IV (Case 3), there is a problem that the input voltage source is short-circuited within the reverse recovery time because a switch is turned on while the adjacent antiparalleled diode $D_{3}$ or $D_{1}$ is still conducting. Thus, the auxiliary circuit is demanded to provide the artificial diode free-wheeling ZVS conditions during these states changes. Hence, by fully utilizing the inherent natural freewheeling of the inverter, the auxiliary circuit only needs to operate when necessary.

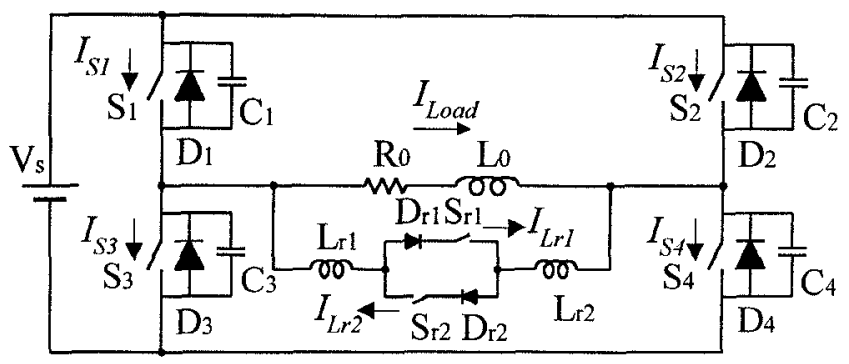

Fig. 1. Single-phase resonant snubber inverter.

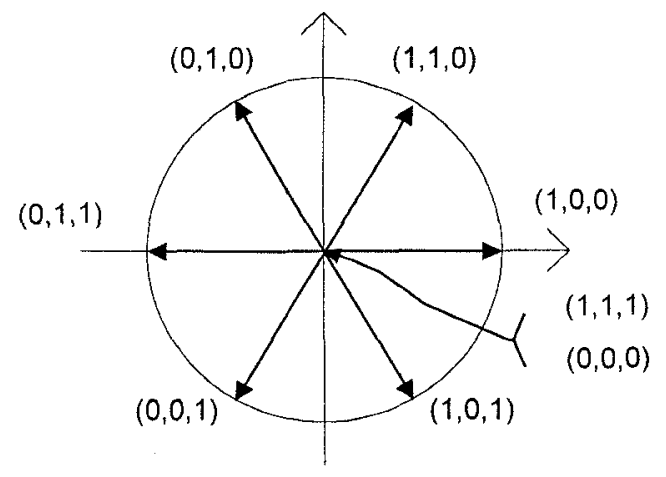

Fig. 2. Space vector PWM.

\section{Soft-Switching Vector}

Considering the widely accepted space vector PWM switching scheme (Fig. 2), there are eight state space vectors which correspond to eight inverter switching states:

$\mathbf{V}_{i}=\left[\alpha_{a}, \alpha_{b}, \alpha_{c}\right]$

$\alpha_{p}=\left\{\begin{array}{l}0 \\ 1\end{array}\right.$

where $i=0,1,2, \ldots, 7$, and $p=a, b, c$. The values of 0 and 1 represent the turn off and turn on of the upper switch, respectively, while the on/off of the lower switch is always opposite to that of the upper one. Since the direction of the load current is important to determine whether the ZVS condition can be naturally achieved, the corresponding direction in phase $p$ is represented as: 
$\beta_{p}=\operatorname{Sign}\left(I_{p}\right)$

where $\beta_{p}$ is +1 for $I_{p}>0$, and -1 for $I_{p}<0$. By changing $\beta_{p}$ to indicate the load current direction, $\gamma_{p}$ is written as:

$\gamma_{p}=\frac{1}{2}\left[1+\beta_{p}\right]=\frac{1}{2}\left[1+\operatorname{Sign}\left(I_{p}\right)\right]$

where $\gamma_{p}$ is 1 for $I_{p}>0$, and 0 when $I_{p}<0$.

In order to determine whether there is natural or artificial ZVS condition, a concept of zero-voltage soft-switching vector is newly defined as:

$S S V_{p}=\alpha_{p} \overline{\gamma_{p}}+\overline{\alpha_{p}} \gamma_{p}$

where $p=a, b, c$. Thus, $S S V_{p}=0$ indicates that there is natural freewheeling which provides the ZVS condition in the leg of phase $p$ without having any assistance from the auxiliary resonant snubber. On the contrary, for $S S V_{p}=1$, the auxiliary circuit needs to operate for achieving the desired ZVS condition. By employing the proposed SSV, the determination of natural ZVS or artificial diode freewheeling ZVS in the leg with $S_{1}$ and $S_{3}$ (defined as phase A) is illustrated in Table 1 . The corresponding zero-voltage SSV for the three-phase inverter can then be represented as:

$\mathbf{S S V}=\left[S S V_{a}, S S V_{b}, S S V_{c}\right]$.

By defining the matrix $\mathbf{C}$ and function $f(x)$, hence $\mathbf{B}$ and $\mathbf{H}$ where $\mathbf{I}$ as an identity matrix:

$$
\begin{aligned}
& \mathbf{C}=\left[\begin{array}{ccc}
I_{a} & 0 & 0 \\
0 & I_{b} & 0 \\
0 & 0 & I_{c}
\end{array}\right] \\
& f(x)=\left\{\begin{array}{cc}
\operatorname{Sign}(x) & x \neq 0 \\
0 & x=0
\end{array}\right. \\
& \mathbf{B}=f(\mathbf{C}) \\
& \mathbf{H}=\frac{1}{2}(\mathbf{I}+\mathbf{B})
\end{aligned}
$$

SSV can be expressed as (11) which can be generated by using simple hardware such as comparators and TTL chips.

$$
\mathbf{S S V}=\mathbf{V}_{i} \mathbf{H}
$$

TABLE I

SSV ANALYSIS FOR PHASE A

\begin{tabular}{|c|c|c|c|c|}
\hline Initial State & Case 1 & Case 2 & Case 3 & Case 4 \\
\hline ON Device & $\mathrm{S}_{1}$ & $\mathrm{D}_{3}$ & $\mathrm{D}_{1}$ & $\mathrm{~S}_{3}$ \\
\hline OFF Device & $\mathrm{S}_{3}$ & $\mathrm{~S}_{1}$ & $\mathrm{~S}_{3}$ & $\mathrm{~S}_{1}$ \\
\hline$\alpha_{a}$ & 1 & 0 & 1 & 0 \\
\hline$I_{a}\left(I_{\text {Load }}\right)$ & positive & positive & negative & negative \\
\hline$\beta_{a}$ & +1 & +1 & -1 & -1 \\
\hline$\gamma_{a}$ & 1 & 1 & 0 & 0 \\
\hline$S S V_{a}$ & 0 & 1 & 1 & 0 \\
\hline Natural ZVS & Yes & No & No & Yes \\
\hline Artificial ZVS & No & Yes & Yes & No \\
\hline
\end{tabular}

\section{SSV CONTROL}

The proposed SSV control can readily be applied to various resonant snubber based inverters. Taking the singlephase delta-configured RSI shown in Fig. 1 for exemplification, its operating modes within one cycle are illustrated in Fig. 3.

\section{A. Without SSV Control}

The principle of operation without using SSV control is described as follows:

Mode $0\left(t<t_{0}\right)$ : This is the initial condition. It is desired to turn off $S_{1}$ and $S_{3}$ and then to turn on $S_{2}$ and $\mathrm{S}_{3}$.

Mode I $\left(\mathrm{t}_{0} \sim \mathrm{t}_{1}\right): \quad \mathrm{S}_{\mathrm{r} 1}$ is turned on at $\mathrm{t}_{1}$ and the resonant inductor current increases linearly, but the current in $\mathrm{S}_{1}$ and $\mathrm{S}_{4}$ also increases and becomes larger than the original value.

Mode $2\left(t_{1} \sim t_{2}\right)$ : At $t_{1}$, the turn off of $S_{1}$ and $S_{3}$ starts the resonance between the resonant inductor and four snubber capacitors. $\mathrm{C}_{1}$ and $\mathrm{C}_{4}$ are charged to full DC-link voltage while $\mathrm{C}_{2}$ and $\mathrm{C}_{3}$ discharged to zero.

Mode $3\left(\mathrm{t}_{2} \sim \mathrm{t}_{3}\right): \quad \mathrm{S}_{2}$ and $\mathrm{S}_{3}$ can be turned on with ZVS and the resonant current begins to decrease.

Mode $4\left(t_{3} \sim t_{4}\right)$ : The resonant inductor current decreases to zero and $\mathrm{S}_{\mathrm{r} 1}$ can be turned off with ZCS. The current is freewheeling via $D_{2}$ and $D_{3}$.

Mode $5\left(\mathrm{t}_{4} \sim \mathrm{t}_{5}\right)$ : At $\mathrm{t}_{4}, \mathrm{~S}_{\mathrm{r} 2}$ is turned on and the resonant inductor current increases linearly. Then, the current in $S_{2}$ and $S_{3}$ reduces linearly and becomes zero at $t_{5}$.

Mode $6\left(\mathrm{t}_{5} \sim \mathrm{t}_{6}\right)$ : The inductor current continues to increase and exceeds the load current while the current in $S_{2}$ and $S_{3}$ changes the direction. When the resonant inductor current increases up to twice of the load current at $\mathrm{t}_{6}, \mathrm{~S}_{2}$ and $\mathrm{S}_{3}$ are turned off.

Mode $7\left(\mathrm{t}_{6} \sim \mathrm{t}_{7}\right)$ : Resonance between the inductor and four capacitors occurs. $\mathrm{C}_{2}$ and $\mathrm{C}_{3}$ are charged to full voltage, while $\mathrm{C}_{1}$ and $\mathrm{C}_{4}$ are discharged to zero at $t_{7}$.

Mode $8\left(\mathrm{t}_{7} \sim \mathrm{t}_{8}\right)$ : The resonant current starts to decrease and the load current is diverted to $D_{1}$ and $D_{4}$. Then, $S_{1}$ and $S_{4}$ can be turned on with ZVS. At $t_{8}$, the resonant current equals the load current, and the diode current is diverted to the switches.

Mode $9\left(t_{8} \sim t_{9}\right)$ : The resonant current continues to decrease linearly. At time $t_{9}$, the resonant current decreases to zero and $S_{\mathrm{r} 2}$ can be turned off with ZCS. After $t_{9}$, the inverter comes back to the initial condition. 


\section{B. With SSV Control}

Mode $0\left(\mathrm{t}<\mathrm{t}_{0}\right)$ : By using the proposed SSV control, the SSV of the inverter can be derived as $[0,0]$ for its two legs. Therefore, the natural ZVS condition can be attained by just turning off the main switches $\mathrm{S}_{1}$ and $\mathrm{S}_{4}$ and no auxiliary circuit assistance is needed. Hence, Mode $1 \sim$ Mode 3 can be skipped and the operation directly goes to Mode 4 as stated above.

Mode $4\left(\mathrm{t}_{3} \sim \mathrm{t}_{4}\right)$ : The current is free-wheeling via $\mathrm{D}_{2}$ and $\mathrm{D}_{3}$ and the main switches $S_{2}$ and $S_{3}$ can be turned on with ZVS. This time, $\mathrm{SSV}=[1,1]$, indicating that the auxiliary circuit need to operate to provide artificial diode freewheeling ZVS condition. Therefore the operation modes followed, namely Mode 5 $\sim$ Mode 9, remain unchanged as above.

By employing the SSV control, the auxiliary circuit only needs to operate about half of the original time, leading to significantly reduce the additional loss and EMI in the auxiliary circuit. Also, the over-current in the main switches in the Mode 1 can be eliminated. The theoretical waveforms without and with SSV control are shown in Fig. 4 and Fig. 5, respectively.
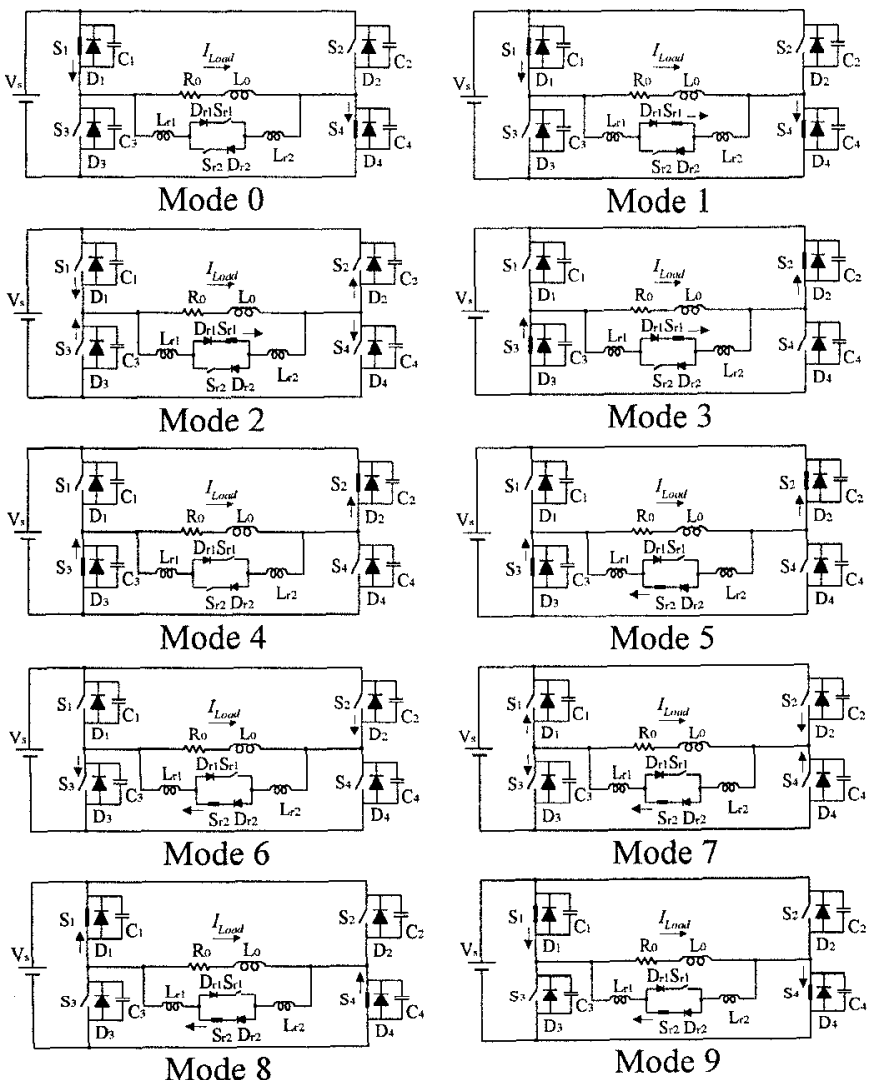

Mode 3

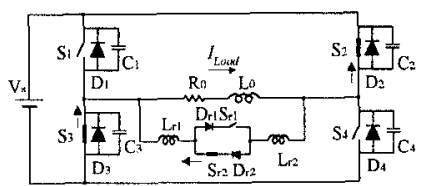

Mode 5

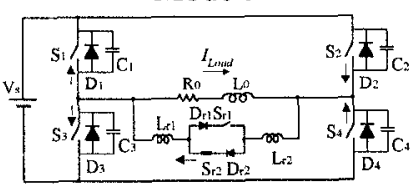

Mode 7

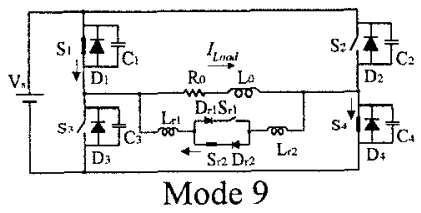

Fig. 3. Modes of operation in one cycle.

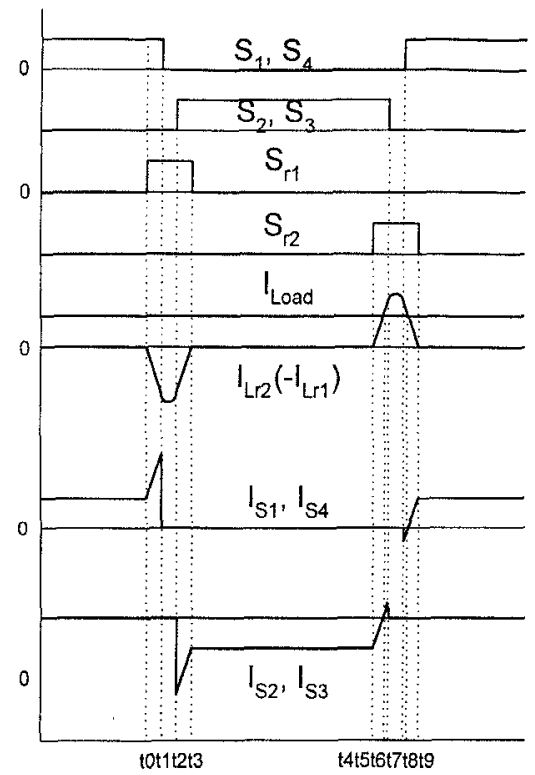

Fig. 4. Theoretical waveforms without SSV.

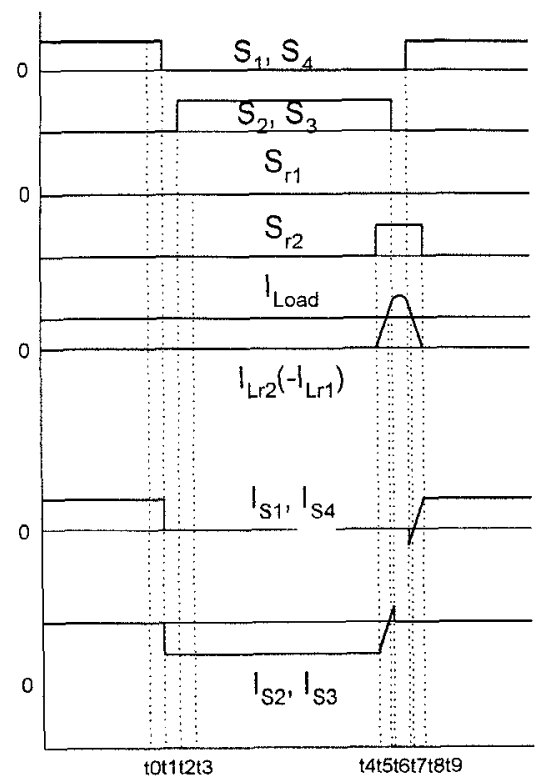

Fig. 5. Theoretical waveforms with SSV.

\section{Improved Version of SSV Control}

Because of the ripples in load current, there will be unnecessary SSV value changing or SSV instabilities within a certain $\delta$-neighborhood of zero load current. This may cause the sudden stop of resonance and the cease of achieving ZVS. Fig. 6 illustrates this phenomenon as found in experiment. Moreover, the load current may not be large enough to conduct natural free-wheeling at this area. Both of them can cause hard-switching or soft-switching losing. To 
avoid these cases, an improved version of SSV is derived.

By adopting hysteresis comparators, the load current direction can be restated as:

$$
\begin{aligned}
& \beta_{1 p}=\operatorname{Sign}\left[I_{p}-\delta \operatorname{Sign}\left(\frac{\Delta I_{p}}{\Delta t}\right)\right] \\
& \beta_{2 p}=\operatorname{Sign}\left[I_{p}+\delta \operatorname{Sign}\left(\frac{\Delta I_{p}}{\Delta t}\right)\right]
\end{aligned}
$$

where

$$
\Delta I_{p}=I_{p}\left(t+\frac{1}{2} \Delta t\right)+I_{p}\left(t-\frac{1}{2} \Delta t\right)
$$

The values of $\delta, \Delta I_{p}$ and $\Delta t$ can be determined by referring to the amplitude of the load current ripple accordingly. With the same procedure as before, the Boolean values indicating the load current direction can be obtained as:

$$
\begin{aligned}
& \gamma_{1 p}=\frac{1}{2}\left[1+\beta_{1 p}\right] \\
& \gamma_{2 p}=\frac{1}{2}\left[1+\beta_{2 p}\right]
\end{aligned}
$$

Then the SSV of a certain phase can be expressed as:

$$
S S V_{p}=\alpha_{p}\left(\overline{\gamma_{1 p}}+\overline{\gamma_{2 p}}\right)+\overline{\alpha_{p}}\left(\gamma_{1 p}+\gamma_{2 p}\right) \text {. }
$$

The corresponding three-phase SSV has the same format as (6) which can be derived as follows:

$$
\begin{aligned}
& \mathbf{B}_{1}=f\left[\mathbf{C}-\delta f\left(\frac{\Delta \mathbf{C}}{\Delta t}\right)\right] \\
& \mathbf{B}_{2}=f\left[\mathbf{C}+\delta f\left(\frac{\Delta \mathbf{C}}{\Delta t}\right)\right] \\
& \mathbf{H}_{1}=\frac{1}{2}\left(\mathbf{I}+\mathbf{B}_{1}\right) \\
& \mathbf{H}_{2}=\frac{1}{2}\left(\mathbf{I}+\mathbf{B}_{2}\right) \\
& \mathbf{S S V}=\mathbf{V}_{i}\left(\overline{\mathbf{H}}_{1}+\overline{\mathbf{H}}_{2}\right)+\overline{\mathbf{V}}_{i}\left(\mathbf{H}_{1}+\mathbf{H}_{2}\right)
\end{aligned}
$$

where all the elements in $\mathbf{H}_{1}$ and $\mathbf{H}_{2}$ have Boolean values.

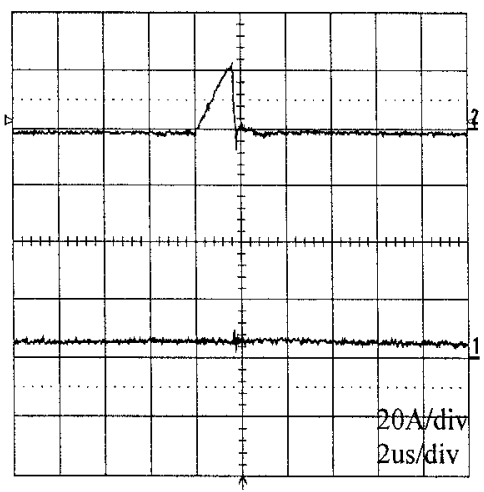

Fig. 6. Phenomenon of resonance sudden stop; upper trace: resonant inductor current; lower trace: load current.
The difference between this improved version of SSV and the original one is slight, but it can avoid the effects due to current ripples and the nearly zero load current. It enables the artificial diode free-wheeling ZVS within the $\delta$-neighborhood of zero load current while the SSV values at other area remain unchanged.

\section{RESULT}

The hardware implementation of this SSV control can be easily realized as shown in Fig. 7. And the improved one can be realized by using hysteresis comparators. A prototype of the delta-configured RSI is constructed with the main switches using TOSHIBA IGBT MG100H2YS1, auxiliary switches using IR IGBT IRGBC30KD2, resonant inductor of $5 \mu \mathrm{H}$ and snubber capacitors of $47 \mathrm{nF}$.

Fig. 8 shows the ZVS condition of a power device, whose voltage drops to zero before the turn on of the applied gate signal. The experimental waveforms with and without using SSV control are shown in the right and left columns of Fig. 9, respectively. As expected, they illustrate both the ZVS condition and mode skipping. These waveforms can fully support the proposed concept and verify the theoretical analysis.

Under the fan cooling condition, when the inverter is operated with a DC-link voltage of $120 \mathrm{~V}$, it can be found that the temperature rise of the heat sink for main switches and auxiliary switches are $12{ }^{\circ} \mathrm{C}$ and $46{ }^{\circ} \mathrm{C}$ when SSV control is inactivated. With the use of SSV control, the corresponding temperature rises are only $7{ }^{\circ} \mathrm{C}$ and $7{ }^{\circ} \mathrm{C}$, demonstrating the significant reduction in the inverter switching loss. The measured data of RSI power loss for both with and without SSV control is shown in Fig. 10, which shows the significant difference in power loss for both cases.

It should be noted that the proposed SSV concept can readily be applied to RSI and other resonant snubber based inverter control without requiring any additional current/voltage sensors in the inverter legs.

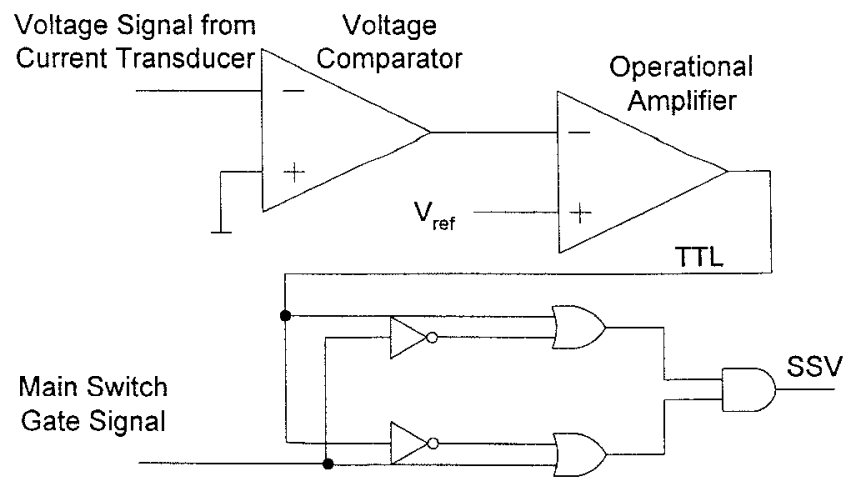

Fig. 7. Implementation of SSV control. 


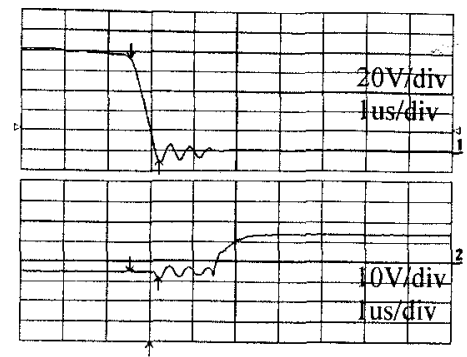

Fig. 8. ZVS waveforms of device voltage (upper trace) and gate signal (lower trace)

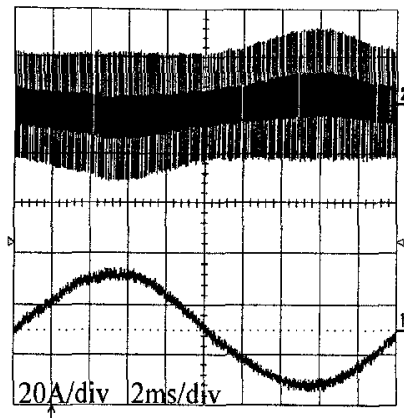

(a) One cycle

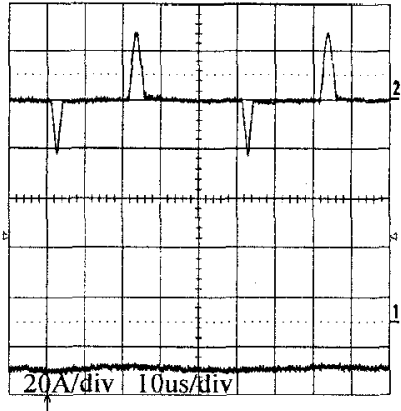

(c) Negative load current

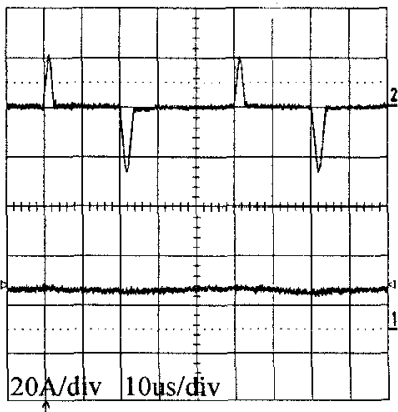

(e) Positive load current

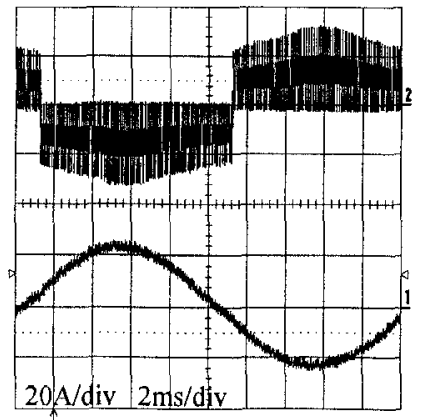

(b) One cycle

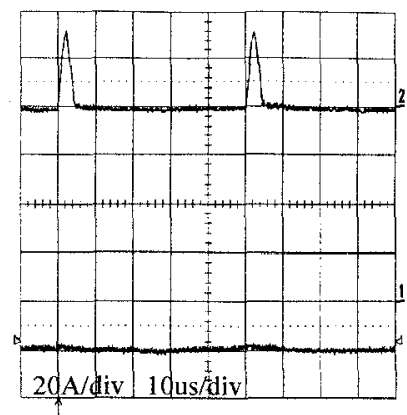

(d) Negative load current

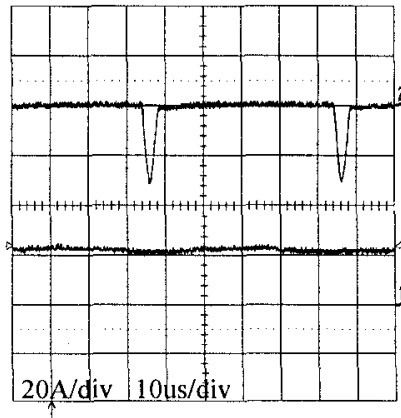

(f) Positive load current
Fig. 9. Resonant inductor current (upper) and load current (lower) waveforms without SSV (left) and with SSV (right).

\section{ACKNOWLEDGMENT}

This work was supported and funded in part by the Committee on Research and Conference Grants, the University of Hong Kong.

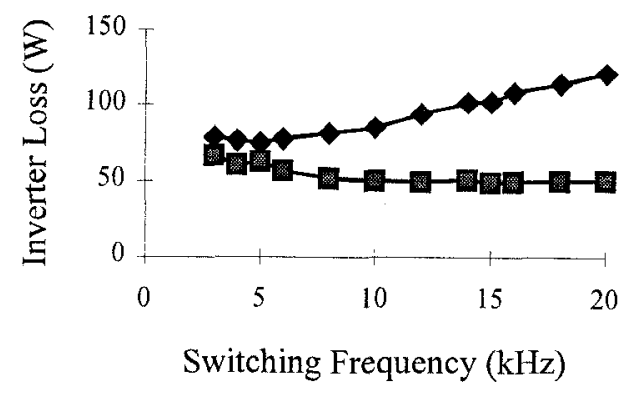

Fig. 10. Power losses without SSV (upper) and with SSV (lower).

\section{CONCLUSION}

In this paper, a new concept of zero-voltage SSV is presented which can readily be applied to control various resonant snubber based inverters. The proposed SSV functions to determine whether the natural ZVS condition occurs or the auxiliary resonant circuit needs to artificially provide the ZVS condition. It has been verified both theoretically and experimentally that the switching loss and EMI of the delta-configured RSI can be significantly reduced by adopting the SSV control. The hardware implementation of this SSV control can be carried out with simple circuitry and there is no need to include any current/voltage sensors in the inverter legs.

\section{REFERENCES}

[1] D.M. Divan, "Resonant dc link converter - a new concept in static power conversion," In Proceedings of IEEE IAS Annual Meeting, 1986, pp. 648-656.

[2] R.W. DeDoncker and J.P. Lyons, "The auxiliary quasiresonant dc link inverter," In Proceedings of IEEE PESC, 1991, pp. 248-253.

[3] V. Vlatkovic, D. Borojevic, F.C. Lee, C. Cuadros and S. Gataric, "A new zero-voltage transition, three-phase PWM rectifier/inverter circuit," In Proceedings of IEEE PESC, 1993, pp. 868-873.

[4] J.S. Lai, "Resonant snubber based soft-switching inverters for electric propulsion drives," In Proceedings of IEEE IECON, 1996, pp. 47-52.

[5] J.S. Lai, R.W. Young, Sr., G.W. Ott, Jr., J.W. McKeever and F.Z. Peng, "A delta-configured auxiliary resonant snubber inverter," IEEE Trans. Industrial Applications, vol. 32, no. 3, 1996, pp. 518-525.

[6] Y.L. Lin and A.F. Witulski, "A unified treatment of a family of ZVS and ZCS resonant inverters," In Proceedings of IEEE PESC, 1997, pp. 14-20. 